University of Nebraska - Lincoln

DigitalCommons@University of Nebraska - Lincoln

April 2005

\title{
Seismic signals are crucial for male mating success in a visual specialist jumping spider (Araneae: Salticidae)
}

\author{
Damian O. Elias \\ Cornell University, Seeley G. Mudd Hall, Ithaca, NY \\ Eileen Hebets \\ University of Nebraska - Lincoln, ehebets2@unl.edu \\ Ronald R. Hoy \\ Department of Neurobiology and Behavior, Cornell University, USA \\ Andrew C. Mason \\ University of Toronto at Scarborough, Toronto, ON MIC 1A4, Canada
}

Follow this and additional works at: https://digitalcommons.unl.edu/bioscihebets

Part of the Behavior and Ethology Commons

Elias, Damian O.; Hebets, Eileen; Hoy, Ronald R.; and Mason, Andrew C., "Seismic signals are crucial for male mating success in a visual specialist jumping spider (Araneae: Salticidae)" (2005). Eileen Hebets Publications. 15.

https://digitalcommons.unl.edu/bioscihebets/15

This Article is brought to you for free and open access by the Papers in the Biological Sciences at DigitalCommons@University of Nebraska - Lincoln. It has been accepted for inclusion in Eileen Hebets Publications by an authorized administrator of DigitalCommons@University of Nebraska - Lincoln. 
Published in Animal Behaviour 69:4 (April 2005), pp. 931-938; doi:10.1016/j.anbehav.2004.06.024

Copyright (C) 2004 The Association for the Study of Animal Behaviour; published by Elsevier Ltd. Used by permission. http://www.sciencedirect.com/science/journal/00033472

Submitted February 15, 2004; revised April 21, 2004; accepted June 15, 2004; published online February 8, 2005.

\title{
Seismic signals are crucial for male mating success in a visual specialist jumping spider (Araneae: Salticidae)
}

Damian O. Elias, Department of Neurobiology and Behavior, Cornell University, Seeley G. Mudd Hall, Ithaca, NY 14853, USA (Corresponding author)

Eileen A. Hebets, Department of Neurobiology and Behavior, Cornell University, USA

(Current address: Division of Insect Biology, Department of Environmental Science, Policy, and Management, University of California, Berkeley, CA 94720, USA)

Ronald R. Hoy, Department of Neurobiology and Behavior, Cornell University, USA

Andrew C. Mason, Integrative Behaviour and Neuroscience, Department of Life Sciences, University of Toronto at Scarborough, Toronto, ON MIC 1A4, Canada

\begin{abstract}
The diversity of courtship displays throughout the animal kingdom is immense and displays can range from seemingly simple, to incredibly complex. Signalers often possess elaborate morphological adaptations for signals directed at a specific sensory modality in receivers. In some cases, these signals are so compelling to human observers, the possibility that important signals exist in other sensory modalities is ignored, potentially resulting in an incomplete characterization of the communication system. J umping spiders (Salticidae) have remarkable visual capabilities. Yet one species, Habronattus dossenus, has recently been shown to have a complex repertoire of multicomponent seismic courtship signals in addition to and produced in concert with its multiple visual ornaments and movement displays. Here, we demonstrate the importance of these seismic signals in the courtship display of $\mathrm{H}$. dossenus by comparing mating frequencies across experimentally manipulated treatments. Virgin females were paired with males from one of two experimental groups: nonmuted males or muted males. We found that females were significantly more likely to copulate with nonmuted males than with muted males. Furthermore, in all pairs that copulated, the latency to copulation was significantly shorter in nonmuted pairings than in muted pairings and precopulatory cannibalism rates were significantly lower. These results demonstrate that seismic signals are a critical component of male $\mathrm{H}$. dossenus courtship displays. Additionally, we demonstrate that many other Habronattus species include a diversity of seismic signals in their courtship displays and we discuss potential selection pressures that may drive the evolution of multimodal displays even in species that already possess elaborate morphological adaptations for signals directed at one sensory modality.
\end{abstract}

The communication signals that mediate mating decisions between males and females are among the most thoroughly investigated behavioral acts in ethology and behavioral ecology (Bradbury \& Vehrencamp 1998). The classification of signal salience is naturally affected by their conspicuousness to human investigators and in some animals, the conspicuousness of a given signal modality is accompanied by obvious adaptations in the morphology of the animals. We tend to think of these animals as sensory specialists. Such is the case for vision in jumping spiders (Salticidae) (Peckham and Peckham, 1889; Peckham and Peckham, 1890; Crane, 1949; Forster, 1982b; Jackson, 1982; Land, 1985; Foelix, 1996). J umping spiders are unique among spiders in possessing a pair of large, frontal eyes (principal eyes) that form true im- ages upon a retina and which confer a degree of spatio-visual acuity unknown in other spiders or even insects (Land, 1985; Land and Nilsson, 2002). While this highly advanced visual system may have its origins in prey capture, both males and females have large principal eyes (AM, anterior median eyes), many jumping spiders have a striking sexual dimorphism in which males possess species-typical, extravagant and exaggerated morphological modifications of limbs, pedipalps, mouthparts and abdomen, including bright and contrasting colors (Peckham and Peckham, 1889; Peckham and Peckham, 1890; Crane, 1949). This has led to extensive studies of courtship signaling of many species, all of which focus nearly exclusively on the conspicuous visual signals of the males, described metaphorically as "semaphores." From 
prior studies of jumping spiders it would be a reasonable inference that most mating decisions are based solely on the assessment of visual signals (Clark and Uetz, 1990; Clark and Uetz, 1993; Clark and Morjan, 2001; Clark and Biesiadecki, 2002). This however, is not always the case. For example, presumptively "primitive" jumping spiders can communicate with chemical stimuli (Crane, 1949; Jackson, 1982). In other more derived taxa, courtship displays can incorporate vibrations (seismic signals) (J ackson, 1977a; Jackson, 1982; Elias et al., 2003), percussion (Noordam 2002) and airborne sound (Edwards, 1981; Gwynne and Dadour, 1985; Maddison and Stratton, 1988). While prior descriptions of visual, vibratory, percussive and acoustic courtship signals exist, descriptions of displays that incorporate more than one of these modalities remain rare and jumping spiders are still considered to be predominantly visual (Foelix 1996).

It was recently reported that prolonged bouts of courtship in one species, Habronattus dossenus Griswold, in which males use intricate stereotyped movements of their multicolored leg and body parts, are also accompanied by seismic signals (Elias et al. 2003). This led us to question the importance of seismic signaling in jumping spiders and the role of multimodality. Seismic signals are produced using self-generated vibrations that are transmitted through a solid substrate such as soil, sand, plants, and so forth (Narins 2001). Habronattus dossenus males use three independent mechanisms in their courtship displays to produce a repertoire of seismic signals, each temporally coordinated with unique visual displays (Elias et al. 2003). Seismic signals range from long phrases that last for seconds to rapid phasic phrases ( $<200 \mathrm{~ms}$ ) that "punctuate" fast movements of the forelegs (Elias et al. 2003).

Here, we show that these seismic signals strongly influence male mating success and are thus an extremely important component in the courtship displays of $\mathrm{H}$. dossenus. We paired virgin females with either muted or nonmuted males and examined mating success. Muted males could not produce seismic signals but could produce normal visual signals, whereas nonmuted males produced all signals normally (visual and seismic). We found that females were more likely to copulate with nonmuted versus muted males. These findings demonstrate the importance of multimodality for an animal in which communication was previously thought to be exclusively visual and suggest that sexual selection may act on seismic signals as well as on visual signals and ornaments.

Following from this experiment, we examined the courtship displays of several Habronattus species to determine whether seismic signals occur in other species. Habronattus is an extraordinarily diverse genus with over 100 described species in North America alone (Griswold, 1987; Maddison and Hedin, 2003). Like most jumping spiders, members of the Habronattus genus are sexually dimorphic, but unlike typical jumping spiders, Habronattus include some of the most elaborate male ornamentation and visual courtship behaviors (Peckham and Peckham, 1889; Peckham and Peckham, 1890; Griswold, 1987; Maddison and Hedin, 2003). Males perform an elaborate sequence of temporally complex motions of colorful body parts and appendages to their unor- namented female counterparts. Recently it has been shown that sexual selection, specifically on male-specific morphology and behavior, has driven diversification in Habronattus (Masta \& Maddison 2002).

We observed the courtship displays of several Habronattus species and determined that the diversity of ornaments and male-specific visual courtship behaviors finds an equal counterpart in seismic signals. We suggest that sexual selection for signal complexity may drive the evolution of multimodal communication and may potentially play a role in species diversification in Habronattus. In addition, we discuss the potential advantages of multimodal signaling in animals that are seemingly specialized for communication in one sensory modality.

\section{Methods}

\section{Spiders}

Mature male and immature female $\mathrm{H}$. dossenus were fieldcollected during March-April 2003 in southwest Arizona, U.S.A., from the Atascosa Mountains, Coronado National Park, Santa Cruz County. Animals were housed individually in plastic containers (AMAC Plastic Products, Petaluma, California, U.S.A.) and kept in the laboratory on a 12:12 h light: dark cycle. Once a week, spiders were fed a diet of fruit flies (Drosophila melanogaster) and crickets (Acheta domesticus). Immature females were checked daily to determine whether they had moulted to maturity. Only virgin adult females aged 16-31 days postmaturation (average $\pm \mathrm{SD}=22 \mathrm{~d}$ ays \pm 2.5 ) were tested in trials. All male and female spiders were fed 2 days before experiments.

\section{Experimental trials}

Mature males were assigned to one of two treatments: (1) muted or (2) nonmuted. Two days before the experiments, males were anaesthetized with $\mathrm{CO}_{2}$ and a piece of bee's wax was placed either (1) between the prosoma and opisthosoma (the first and second body regions), ultimately connecting the two and inhibiting their relative movement (muted) or (2) on top of the prosoma but not connecting it to any other body part (nonmuted). This method of fixing the prosoma to the opisthosoma has been shown to eliminate most seismic signals without affecting any visual signals (Elias et al. 2003). A low-intensity percussive component produced by the forelegs is unaffected by this procedure (Elias et al. 2003). Placing wax only on the prosoma does not affect any visual or seismic signals (Elias et al. 2003). We used approximately the same amount of wax for both treatments. To ensure that these treatments did not affect normal locomotory activities, we observed whether or not waxed spiders were able to successfully capture prey during the 2 days following these manipulations. Males were randomly paired with different females. Each female and male was only used once.

A plastic cylinder $(12.5 \mathrm{~cm}$ in diameter $\times 13.5 \mathrm{~cm}$ high) with Vaseline placed on the inside of cylinder wall to prevent spiders from crawling up the sides was used as the courting 
arena. A piece of graph paper cut to fit inside the cylinder was used as the arena floor. An opaque paper ring was placed around the outside of the cylinder to prevent unwanted visual distractions. An EIS fiber-optic light system was used to illuminate the arena. All trials were videotaped (Canon ZR50 MC, 30 frames/s) from above. Graph paper was replaced every two trials to prevent the build up of chemical cues.

Females were placed into the arena first, then males. Trials lasted $15 \mathrm{~min}$. Only males that courted during this time were scored. Courtship in $\mathrm{H}$. dossenus consists of four phases (Elias et al. 2003). Phase 1 consists of only visual signals (Elias et al. 2003), with sidling movements in which the male approaches in a typical salticid "zigzag" visual display (Forster 1982b). During this approach the male waves his forelegs and spreads his pedipalps in a stereotypical fashion. When the male comes to within approximately one body length of the female, multimodal courtship begins. Phases 2 through 4 consist of multiple bouts of prolonged seismic and visual signaling. Seismic displays occur only in phases 24 (Figure 5a). Phases for both treatments were determined by the stereotypic visual components of courtship (Elias et al. 2003). To obtain a realistic measure of mate choice, we measured: (1) presence/ absence of copulation, (2) latency of the beginning of phase 1 courtship to copulation, (3) latency of the beginning of phase 2 courtship to copulation, (4) total phase 1 courtship duration, (5) total multimodal (phases 2-4) courtship duration, and (6) occurrences of premating cannibalism.

Durations of courtship for all treatments were compared using a Student's t test with Bonferroni corrections. Copulation and cannibalism proportions were compared using a Pearson chi-square test. Statistical tests were conducted using the SYSTAT statistical analysis package (SSI, Richmond, California, U.S.A.).

\section{Recording procedures for seismic signals in Habronattus}

Recording procedures were similar to a previous study (Elias et al. 2003). Briefly, we anaesthetized female $H$. dossenus, $H$. cognatus, $\mathrm{H}$. pugillis and $\mathrm{H}$. schlingeri with $\mathrm{CO}_{2}$ and tethered them to a wire with bee's wax. Males of the respective species were then dropped on to the substrate and allowed to court freely. We recorded substrate vibrations produced during courtship using a laser Doppler vibrometer (LDV) (Polytec OFV 3001 controller, OFV 511 sensor head, Waldbronn, Germany) (Michelsen et al. 1982). The LDV signal was recorded on the audio track during standard videotaping of courtship behavior (Navitar Zoom 7000 lens, Panasonic GPKR222, Sony DVCAM DSR-20 digital VCR, $44.1 \mathrm{kHz}$ audio sampling rate). All recordings were made on a vibration-isolated table.

\section{Results}

Male mating success and seismic signaling in $\boldsymbol{H}$. dossenus

Females copulated more frequently with nonmuted males, which could produce seismic signals, than with muted males $\left(\mathrm{x}_{1}^{2}=7.817, \mathrm{P}<0.01\right.$; Figure 1$)$. Males that could produce seismic signals were three times more likely to achieve successful copulation than muted males (Figure 1).

While mating frequency was significantly lower with muted males, seismic signals were not absolutely necessary, because successful copulations did occur in five of the 23 muted male trials. The latency to copulation differed significantly between muted and nonmuted trials (Figure 2). The latency from the start of courtship (phase 1) to copulation was significantly shorter in pairings with nonmuted males than in those with muted males (X \pm SD: nonmuted males: $321.3 \pm 154.4 \mathrm{~s}, \mathrm{~N}=14$; muted males: $591.6 \pm 85.5 \mathrm{~s}$, $\mathrm{N}=5 ; \mathrm{t}_{17}=3.672, \mathrm{P}<0.01$; Figure $2 \mathrm{a}$ ), as was the latency from the start of multimodal courtship (phase 2) to copulation (nonmuted males: $157.1 \pm 81.0 \mathrm{~s}, \mathrm{~N}=14$; muted males: $355.4 \pm 131.5$ s, $N=5 ; t_{17}=3.991, P<0.01$; Figure 2b).

Experimental manipulations did not affect mean courtship duration of phase 1 (visual only) ( $\overline{\mathrm{X}} \pm \mathrm{SD}$ : nonmuted males: $160.1 \pm 115.0 \mathrm{~s}, \mathrm{~N}=24$; muted males: $201.0 \pm 150.0 \mathrm{~s}$, $\mathrm{N}=23$; $\mathrm{t}_{45}=1.040, \mathrm{P}=0.30$; Figure 3 ) or phases $2-4$ courtship (visual + seismic) (nonmuted males: $93.8 \pm 70.8 \mathrm{~s}$, $\mathrm{N}=24$; muted males: $77.4 \pm 115.9 \mathrm{~s}, \mathrm{~N}=23$; $\mathrm{t}_{45}=-0.587$, $\mathrm{P}=0.56$; Fig 3).

Muted males were four times more likely to be cannibalized than nonmuted males $\left(x_{1}^{2}=3.706, P=0.05\right.$; Figure 4$)$.

\section{Diversity of seismic signaling in other Habronattus species}

Figure 5 shows examples of seismic signals and male morphology for $\mathrm{H}$. dossenus as well as three other Habronattus species: H. cognatus, H. pugillis and H. schlingeri. All species examined combine diverse multiple visual ornaments and movement displays with a diversity of complex seismic signals.

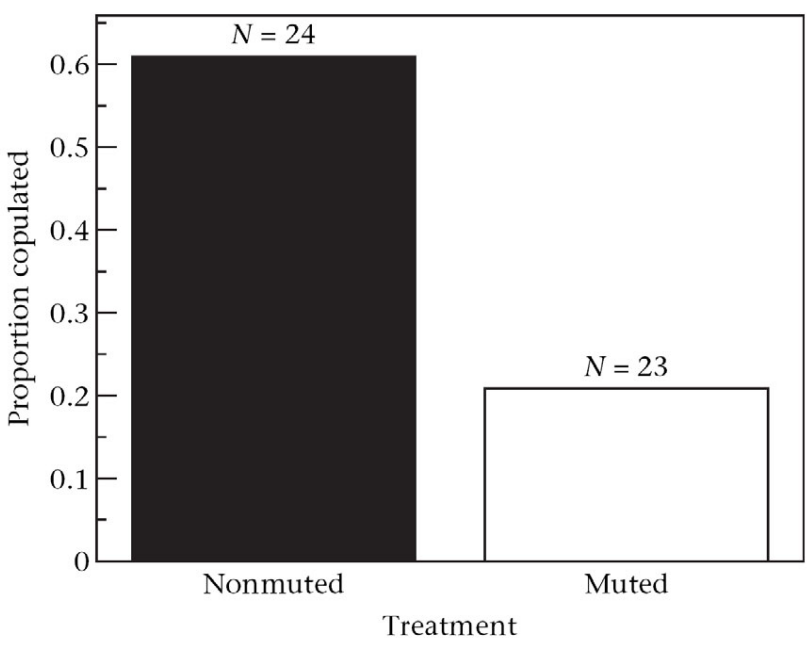

Figure 1. The proportion of muted and nonmuted males that successfully copulated with females. Copulation proportions were compared using a Pearson chi-square test $(P<0.05)$. 
(a)

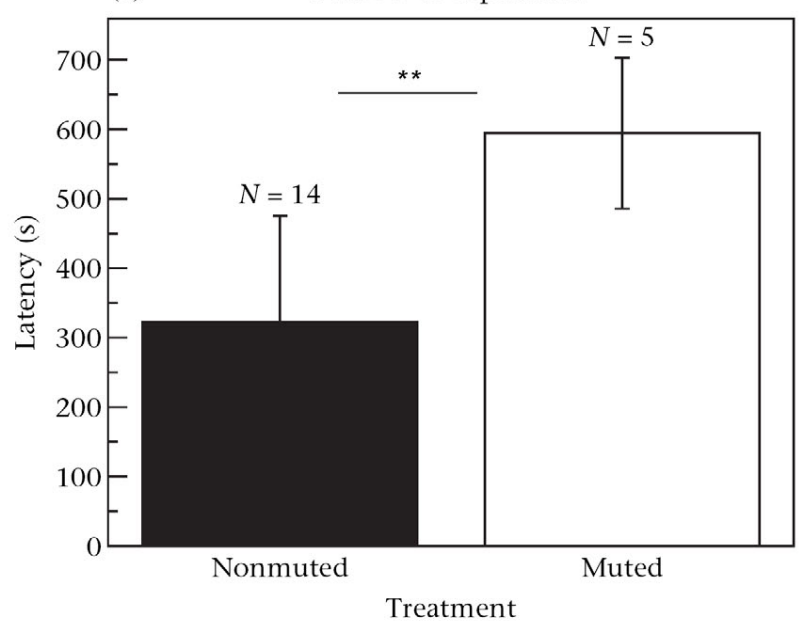

(b) Phase 2 to copulation

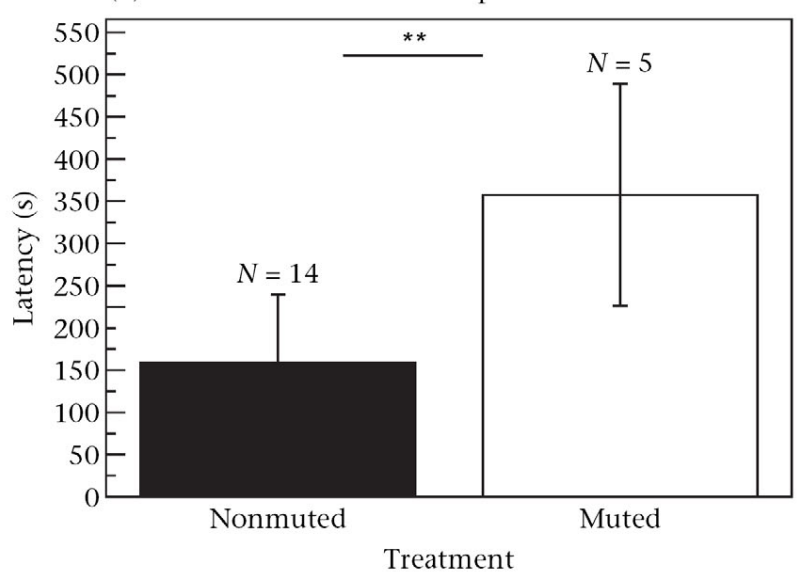

Figure 2. Latency to copulation from (a) phase 1 (visual only) or (b) phase 2 (visual + seismic) courtship. Significant differences $(P<0.05)$ between treatments were tested using a Student's $t$ test with Bonferroni corrections $\left({ }^{* *} P<0.01\right)$.

\section{Discussion}

This study clearly demonstrates that female H. dossenus, previously thought to be visual specialists, base part of their decision to mate on the seismic component of a male's multimodal courtship display, despite the obvious visual ornamentation and displays of $\mathrm{H}$. dossenus males (Griswold 1987). The importance of seismic signals in the multimodal courtship display of $\mathrm{H}$. dossenus was demonstrated by comparing mating frequencies between female pairings with muted versus nonmuted males. Muted males were three times less likely to mate than nonmuted males (Figure 1). There were no differences in the total time males in each treatment spent courting (all phases) (Figure 3), hence male courtship did not vary across treatments and all females had the same opportunity to assess males regardless of treatment.

While seismic signals are clearly important in male courtship displays, they are not entirely necessary to achieve successful copulation, since a minority of females mated with

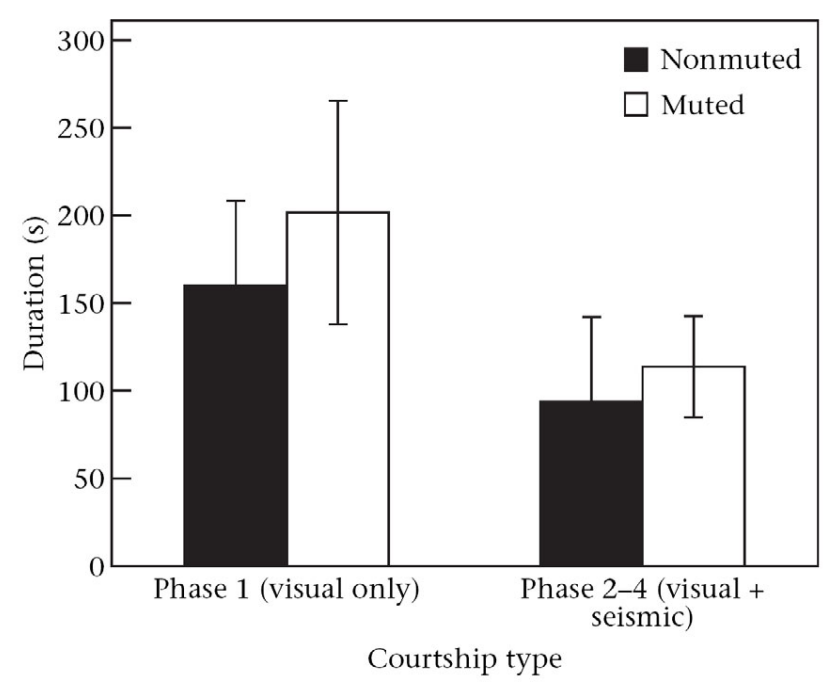

Figure 3. Total time males spent in phase 1 (visual only) and phases 2-4 (multimodal) courtship. Significant differences $(P<0.05)$ between treatments were tested using a Student's $t$ test with Bonferroni corrections.

muted males ( $N=5,21 \%$ of muted male pairings). However, restricting our comparison to only those pairs that copulated, we still found differences between the muted and nonmuted treatments. Latency to copulation from the initiation of courtship, either from the visual-only phase (phase 1) or multimodal (visual + seismic) phase (phase 2), was significantly shorter in nonmuted than in muted treatments (Figure 3). In the field, H. dossenus density can be high, thus it is probable that females will encounter multiple males in a short period (D. O. Elias, unpublished observation). A shorter latency would reduce the opportunity for interference by rival males, thereby giving the courting male an advantage. Shorter latencies would also limit the time that males and females are exposed to predators, since courtship often occurs on exposed surfaces of leaf litter and is likely to draw unwanted attention (Elias et al. 2003). Thus, if assessment of multiple signals by females leads to faster mate choice decisions, multimodal signals may be a general adaptation to minimize courtship time.

Premating cannibalism of males by females in our study was more likely to occur in muted treatments than in nonmuted treatments (Figure 4). The occurrence of sexual cannibalism is common in many spider groups including jumping spiders (Polis, 1981; J ackson, 1982; Jackson, 1977b; Elgar, 1992; Andrade, 1996; Hebets, 2003). Our results suggest two possibilities as to the specific function of seismic signaling components: (1) seismic components are signaling species identity or (2) seismic components are signaling information about male quality. The function of the complex visual courtship displays in jumping spiders has been hypothesized to function in cannibalism deterrence, either by signaling species identity or by the suppression of female aggression (J ackson 1982). The increased instances of cannibalism in muted males suggest that seismic signals may function in these ways for $\mathrm{H}$. dossenus as well. Alternatively, seismic components may be signaling information about male 


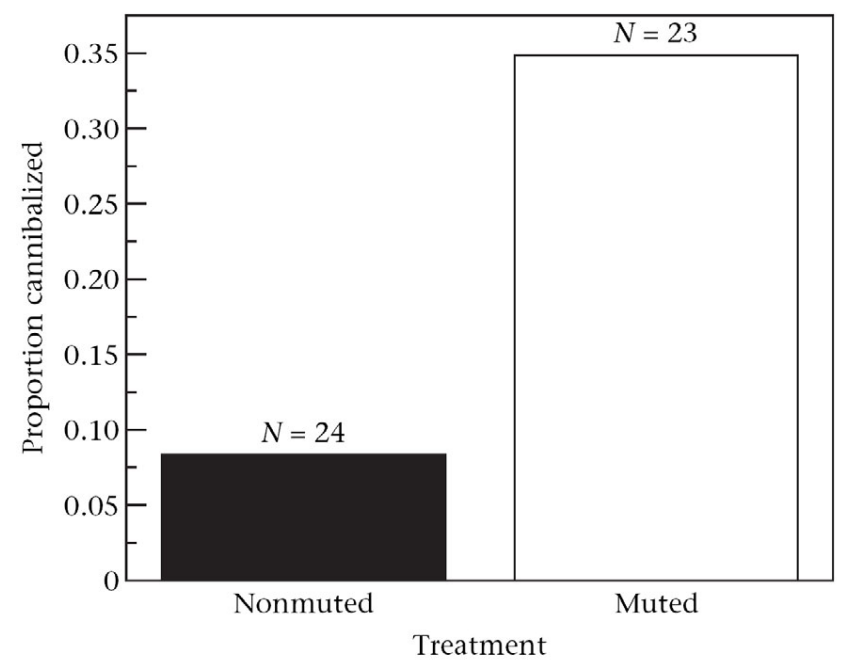

Figure 4. The proportion of muted and nonmuted males that were sexually cannibalized by females. Cannibalized proportions were compared using a Pearson chi-square test $(P<0.05)$.

quality; the higher incidence of cannibalism of muted males could reflect a perceived lower quality of males: females may be more likely to eat low-quality males and mate with highquality males. Future work will explore these possibilities.

The difference in cannibalism rates could also be a result of the application of wax to mute the males. A wax connection between the prosoma and opisthosoma (the first and second body parts) may limit the ability of males to escape attacks from females even though care was taken to use the same amount of wax in both treatments. Jumping spiders catch prey by first stalking and then leaping on them (Forster 1982a). Since courtship behavior brings males in close proximity to females, any manipulation that inhibited escape behaviors would increase the probability that females would cannibalize males and thereby prevent a successful mating. None the less, we observed minimal inhibition of movement and no differences in visual courtship or predatory behaviors in the interval between the treatments. Premating cannibalism by females is therefore unlikely to have been an artifact of our treatments. Regardless, this is a future avenue to explore.

Virtually all previous studies of jumping spider behavior, including mating behavior, have focused on the role of vision, which is highly developed in this group. The primary eyes (anterior median eyes) are specialized for high-resolution vision and include adaptations for color vision (Land, 1969; Eakin and Brandenburger, 1971; Blest et al., 1981, Blest, 1985; Land, 1985), image focusing (Eakin \& Brandenburger 1971) and a telephoto lens (Williams \& McIntyre 1980), providing jumping spiders with visual capacities comparable to many vertebrate eyes (Land \& Nilsson 2002). Secondary eyes (lateral and posterior median eyes) are adapted for high temporal resolution and movement detection (Land, 1971; Duelli, 1978; Forster, 1982b). These visual specializations are associated with a complex repertoire of visually mediated behaviors including prey capture, courtship and agonistic displays (Forster, 1982a; Forster, 1982b; J ackson, 1982; J ackson and
Pollard, 1996). In particular, the courtship displays of jumping spiders have received special attention as examples of visual signaling behaviors (Crane, 1949; Eakin and Brandenburger, 1971; Forster, 1982b; Jackson, 1982; Land, 1985; Bradbury and Vehrencamp, 1998; Land and Nilsson, 2002) mediating species recognition and female choice (Jackson, 1982; Clark and Uetz, 1993; Clark and Morjan, 2001). Complex nonsocial behaviors such as three dimensional route planning (Hill, 1979; Tarsitano and Andrew, 1999) and prey discrimination (Harland \& Jackson 2002) have also been shown to be visually mediated.

The unique visual sense of jumping spiders has been driven by both natural and sexual selection. Certainly, their well-reported and remarkable predatory abilities bespeak natural selection for enhanced vision. Similarly, the interplay of enhanced vision and sexual selection has been implicated in the evolution of courtship displays in the genus Habronattus due to the outstanding degree of complexity and variation in their ornamentation and movement displays (Peckham and Peckham, 1889; Peckham and Peckham, 1890; Masta and Maddison, 2002) as well as their extraordinary morphological and geographical variation (Griswold, 1987; Maddison and McMahon, 2000). Species groups within Habronattus having the most ornaments and the most complex visual displays are also the most species-rich groups (Griswold, 1987; Maddison and Hedin, 2003). This suggests an important role for sexual selection in speciation in this genus (Maddison and McMahon, 2000, Masta, 2000; Masta and Maddison, 2002). We are now finding that this extensive and prominent morphological diversity occurs in conjunction with a corresponding diversity of seismic courtship signals in these groups (Figure 5) (Maddison and Stratton, 1988; Elias et al., 2003). Although a few jumping spider species distantly related to Habronattus also produce vibrational signals (Edwards, 1981; Gwynne and Dadour, 1985; Maddison and Stratton, 1988), the use of the seismic vibratory modality is ubiquitous in many Habronattus species groups (Figure 5) (Maddison and Stratton, 1988; Elias et al., 2003). The present study suggests that seismic signals are a sexually selected trait in $\mathrm{H}$. dossenus, and due to the remarkable diversity of seismic displays in the Habronattus clade (Figure 5), that courtship signal elaboration in the seismic modality may have played a role in the diversification of Habronattus.

Finally, it should not be surprising that multimodal communication may be the rule rather than the exception, even in systems in which animals have exaggerated and specialized signaling and sensory structures common to a single modality. Multimodal communication offers multiple advantages. Cross-modal interactions have been shown to improve signal detection and discrimination thresholds (Rowe, 1999; Recanzone, 2003), and could be a mechanism to overcome constraints on the amount of information that can be effectively transferred in a single modality (channel capacity, Shannon 1949). Complex signals in a single modality are often perceived as a single unified stimulus (Honey and Hall, 1989; Rowe, 1999), whereas information transmitted in multiple modalities is not (Hillis et al. 2002). Furthermore, mul- 
(a)

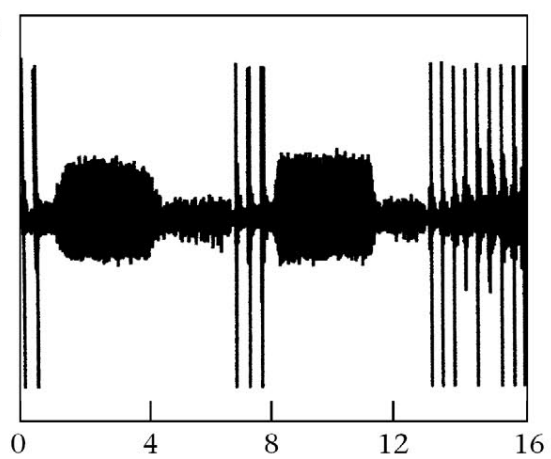

(b)

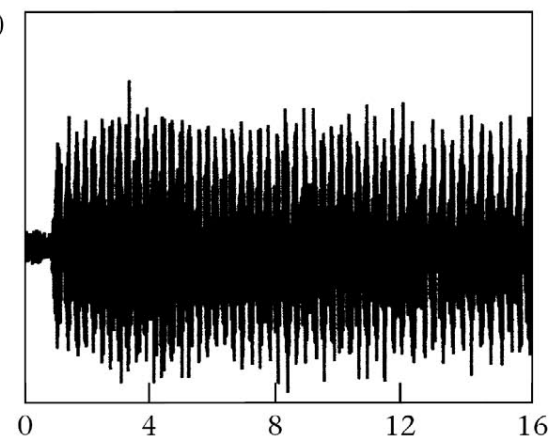

(c)



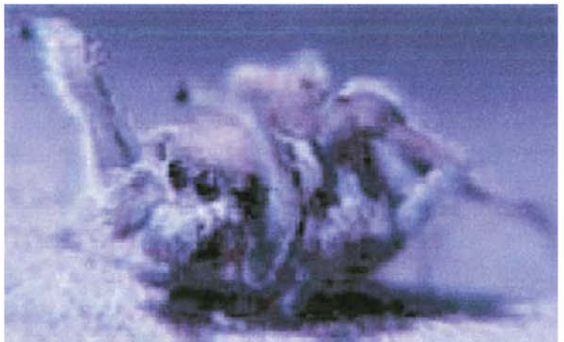
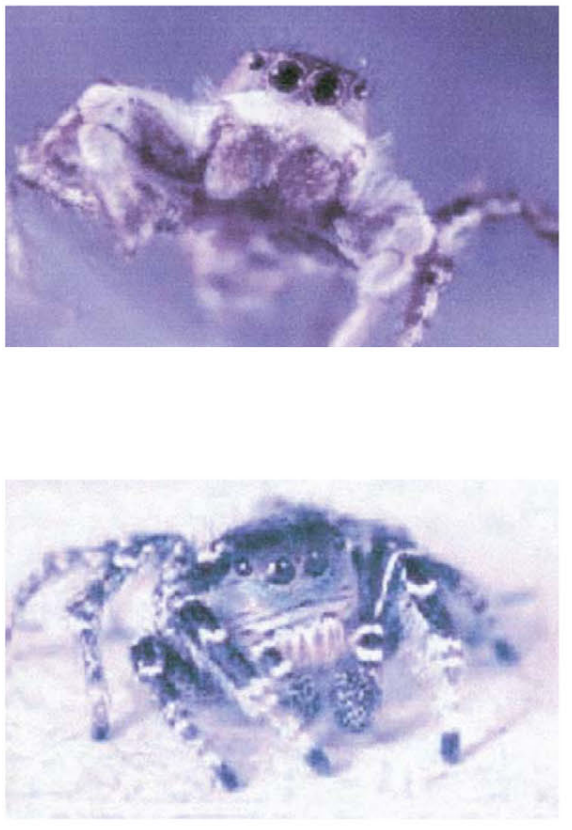

(d)

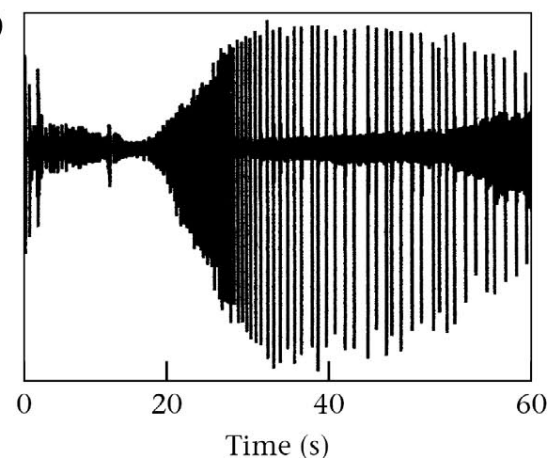

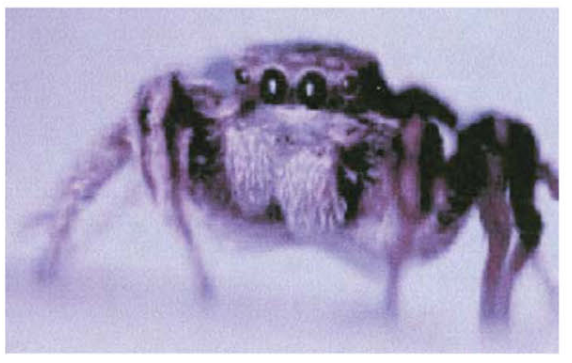

Figure 5. Diversity of seismic signaling in Habronattus. (a) H. dossenus Griswold (clypeatus group) courtship. (b) H. cognatus (Peckham \& Peckham) (agilis group) courtship. (c) H. pugillis Griswold (pugillis group, Atascosa form) courtship. (d) H. schlingeri (Griswold) (coecatus group) courtship. Seismic signals produced during courtship were recorded using a laser Doppler vibrometer.

timodal signals can function to overcome noise in one modality by retaining clarity in another (backup signals: J ohnstone, 1996; Rowe, 1999). A multimodal signal produced as an integrated whole also may be more than the sum of its parts due to the potential emergent cross-modal properties of multiple signals (Partan and Marler, 1999; Hebets and Papaj, in press). It follows, therefore, that selection favoring increased signal complexity (such as sexual selection for elaborate courtship displays) would favor multimodality when additional sensory channels are available. In any event, we propose that courtship communication in jumping spiders is an attractive model communication system for future studies of behavioral ecology, sensory integration, and the role of sexual selection in speciation. 


\section{Acknowledgments}

We thank M. C. B. Andrade, C. Gilbert, G. Patricelli, N. VanderSal, K. Fowler-Finn, W. P. Maddison, M. Hedin, M. Lowder, S. E. Masta, A. Lucero, NBB Behavioral "Lunch Bunch" and members of the Hoy laboratory for helpful comments, suggestions and assistance. Funding was provided by the Natural Science and Engineering Research Council of Canada to A.C.M. (238882 241419), National Institutes of Health to R.R.H. (N1DCRo1 DCo0103), an National Institute of Mental Health training grant to E.A.H. (2 T32 MH15793), and a Howard Hughes Medical Institute Pre-Doctoral Fellowship to D.O.E.

\section{References}

Andrade, 1996 - M. C. B. Andrade, Sexual selection for male sacrifice in the Australian redback spider, Science 271 (1996), pp. 70-72.

Blest, 1985 - A.D. Blest, The fine structure of spider photoreceptors in relation to function. In: F. G. Barth, Editor, Neurobiology of Arachnids, Springer-Verlag, New York (1985), pp. 79-102.

Blest et al., 1981 - A. D. Blest, R. C. Hardie, P. Mclntyre and D. S. Williams, The spectral sensitivities of identified receptors and the function of retinal tiering in the principal eyes of a jumping spider, Journal of Comparative Physiology 145 (1981), pp. 227-239.

Bradbury and Vehrencamp, 1998 - J. W. Bradbury and S. L. Vehrencamp, Principles of Animal Communication, Sinauer, Sunderland, Massachusetts (1998).

Clark and Biesiadecki, 2002 - D. L. Clark and B. Biesiadecki, Mating success and alternative reproductive strategies of the dimorphic jumping spider, Maevia inclemens (Araneae, Salticidae), Journal of Arachnology 30 (2002), pp. 511-518.

Clark and Morjan, 2001 - D. L. Clark and C. L. Morjan, Attracting female attention: the evolution of dimorphic courtship displays in the jumping spider Maevia inclemens (Araneae: Salticidae), Proceedings of the Royal Society of London, Series B 268 (2001), pp. 2461-2465.

Clark and Uetz, 1990 - D. L. Clark and G.W. Uetz, Video image recognition by the jumping spider, Maevia inclemens (Araneae: Salticidae), Animal Behaviour 40 (1990), pp. 884-890.

Clark and Uetz, 1993 - D. L. Clark and G.W. Uetz, Signal efficacy and the evolution of male dimorphism in the jumping spider, Maevia inclemens, Proceedings of the National Academy of Sciences, U.S.A. 90 (1993), pp. 11954-11957.

Crane, 1949 - J. Crane, Comparative biology of salticid spiders at Rancho Grande, Venezuela. Part IV. An analysis of display, Zoologica 34 (1949), pp. 159-214.

Duelli, 1978 - P. Duelli, Movement detection in posterolateral eyes of jumping spiders (Evarcha arcuata, Salticidae), Journal of Comparative Physiology 124 (1978), pp. 15-26.

Eakin and Brandenburger, 1971 - R. M. Eakin and J. L. Brandenburger, Fine structure of the eyes of jumping spiders, Journal of Ultrastructure Research 37 (1971), pp. 618-663.
Edwards, 1981 - G. B. Edwards, Sound production by courting males of Phidippus mystaceus (Araneae: Salticidae), Psyche 88 (1981), pp. 199-214.

Elgar, 1992 - M. Elgar, Sexual cannibalism in spiders and other invertebrates. In: M. Elgar and B. Crespi, Editors, Cannibalism: Ecology and Evolution among Diverse Taxa, Oxford University Press, Oxford (1992), pp. 128-155.

Elias et al., 2003 - D. O. Elias, A. C. Mason, W. P. Maddison and R.R. Hoy, Seismic signals in a courting male jumping spider (Araneae: Salticidae), Journal of Experimental Biology 206 (2003), pp. 4029-4039.

Foelix, 1996 - R. F. Foelix, The Biology of Spiders, Oxford University Press, New York (1996).

Forster, 1982a - L. Forster, Vision and prey-catching strategies in jumping spiders, American Scientist 70 (1982), pp. 165-175.

Forster, 1982b - L. Forster, Visual communication in jumping spiders (Salticidae). In: P.N. Witt and J. S. Rovner, Editors, Spider Communication: Mechanisms and Ecological Significance, Princeton University Press, Princeton, New Jersey (1982), pp. 161-212.

Griswold, 1987 - C. E. Griswold, A revision of the jumping spider genus Habronattus F.O.P. Cambridge (Araneae: Salticidae) with phenetic and cladistic analyses, University of California Publications in Entomology 107 (1987), pp. 1-344.

Gwynne and Dadour, 1985 - D. T. Gwynne and I. R. Dadour, A new mechanism of sound production by courting male jumping spiders (Araneae: Salticidae, Saitis michaelseni Simon), Zoological Society of London 207 (1985), pp. 35-42.

Harland and Jackson, 2002 - D. P. Harland and R.R. Jackson, Influence of cues from the anterior medial eyes of virtual prey on Portia fimbriata, an araneophagic jumping spider, Journal of Experimental Biology 205 (2002), pp. 1861-1868.

Hebets, 2003 - E. A. Hebets, Subadult experience influences adult mate choice in an arthropod: exposed female wolf spiders prefer males of a familiar phenotype, Proceedings of the National Academy of Sciences, U.S.A. 100 (2003), pp. 13390-13395.

Hebets and Papaj, in press - Hebets, E. A. \& Papaj, D. R. In press. Complex signal function: developing a framework of testable hypotheses. Behavioral Ecology and Sociobiology, doi: 10.1007/S0026004-0865-7.

Hill, 1979 - D. E. Hill, Orientation by jumping spiders of the genus Phiddipus (Araneae: Salticidae) during the pursuit of prey, Behavioral Ecology and Sociobiology 5 (1979), pp. 301-322.

Hillis et al., 2002 - J. M. Hillis, M. O. Ernst, M.S. Banks and M.S. Landy, Combining sensory information: mandatory fusion within, but not between, senses, Science 298 (2002), pp. 1627-1630.

Honey and Hall, 1989 - R. C. Honey and G. Hall, Attenuation of latent inhibition after compound pre-exposure: associative and perceptual explanations, Quarterly Journal of Experimental Psychology B 41 (1989), pp. 335-368.

Jackson, 1977a - R.R. Jackson, Courtship versatility in the 
jumping spider, Phidippus johnsoni (Araneae: Salticidae), Animal Behaviour 25 (1977), pp. 953-957.

Jackson, $1977 \mathbf{b}$ - R.R. Jackson, Prey of the jumping spider Phiddipus johnsoni (Araneae: Salticidae), Journal of Arachnology 5 (1977), pp. 145-149.

Jackson, 1982 - R.R. Jackson, The behavior of communicating in jumping spiders (Salticidae). In: P.N. Witt and J. S. Rovner, Editors, Spider Communication: Mechanisms and Ecological Significance, Princeton University Press, Princeton, New Jersey (1982), pp. 213-247.

Jackson and Pollard, 1996 - R.R. Jackson and S.D. Pollard, Predatory behavior of jumping spiders, Annual Review of Entomology 41 (1996), pp. 287-308.

Johnstone, 1996 - R. A. Johnstone, Multiple displays in animal communication: 'backup signals' and 'multiple messages', Philosophical Transactions of the Royal Society of London, Series B 351 (1996), pp. 329-338.

Land, 1969 - M. F. Land, Structure of retinae of principal eyes of jumping spiders (Salticidae: Dendryphantinae) in relation to visual optics, Journal of Experimental Biology 51 (1969), pp. 443-470.

Land, 1971 - M. F. Land, Orientation by jumping spiders in absence of visual feedback, Journal of Experimental Biology 54 (1971), pp. 119-139.

Land, 1985 - M. F. Land, The morphology and optics of spider eyes. In: F. G. Barth, Editor, Neurobiology of Arachnids, Springer-Verlag, Berlin (1985), pp. 53-78.

Land and Nilsson, 2002 - M. F. Land and D.-E. Nilsson, Animal Eyes, Oxford University Press, Oxford (2002).

Maddison and Hedin, 2003 - W. Maddison and M. Hedin, Phylogeny of Habronattus jumping spiders (Araneae: Salticidae), with consideration of genital and courtship evolution, Systematic Entomology 28 (2003), pp. 1-21.

Maddison and McMahon, 2000 - W. Maddison and M. McMahon, Divergence and reticulation among montane populations of a jumping spider (Habronattus pugillis Griswold), Systematic Biology 49 (2000), pp. 400-421.

Maddison and Stratton, 1988 - W. P. Maddison and G. E. Stratton, Sound production and associated morphology in male jumping spiders of the Habronattus agilis species group (Araneae, Salticidae), Journal of Arachnology 16 (1988), pp. 199-211.

Masta, 2000 - S.E. Masta, Phylogeography of the jumping spider Habronattus pugillis (Araneae: Salticidae): recent vicariance of sky island populations?, Evolution 54 (2000), pp. 1699-1711.
Masta and Maddison, 2002 - S.E. Masta and W. P. Maddison, Sexual selection driving diversification in jumping spiders, Proceedings of the National Academy of Sciences, U.S.A. 99 (2002), pp. 4442-4447.

Michelsen et al., 1982 - A. Michelsen, F. Fink, M. Gogala and D. Traue, Plants as transmission channels for insect vibrational songs, Behavioral Ecology and Sociobiology 11 (1982), pp. 269-281.

Narins, 2001 - P.M. Narins, Vibration communication in vertebrates. In: F. G. Barth and A. Schmid, Editors, Ecology of Sensing, Springer-Verlag, Berlin (2001), pp. 127-149.

Noordam, 2002 - A. P. Noordam, Abdominal percussion and ventral scutum in male Euophrys frontalis (Araneae: Salticidae), Entomologische Berichten Amsterdam 62 (2002), pp. 17-19.

Partan and Marler, 1999 - S. Partan and P. Marler, Communication goes multimodal, Science 283 (1999), pp. 1272-1273.

Peckham and Peckham, 1889 - G.W. Peckham and E.G. Peckham, Observations on sexual selection in spiders of the family Attidae, Occasional Papers of the Wisconsin Natural History Society 1 (1889), pp. 3-60.

Peckham and Peckham, 1890 - G.W. Peckham and E.G. Peckham, Additional observations on sexual selection in spiders of the family Attidae, with some remarks on Mr. Wallace's theory of sexual ornamentation, Occasional Papers of the Wisconsin Natural History Society 1 (1890), pp. 117-151.

Polis, 1981 - G. Polis, The evolution and dynamics of intraspecific predation, Annual Review of Ecology and Systematics 12 (1981), pp. 225-251.

Recanzone, 2003 - G.H. Recanzone, Auditory influences on visual temporal rate perception, Journal of Neurophysiology 89 (2003), pp. 1078-1093.

Rowe, 1999 - C. Rowe, Receiver psychology and the evolution of multicomponent signals, Animal Behaviour 58 (1999), pp. 921-931.

Shannon, 1949 - C. E. Shannon, The Mathematical Theory of Communication, University of Illinois Press, Urbana (1949).

Tarsitano and Andrew, 1999 - M.S. Tarsitano and R. Andrew, Scanning and route selection in the jumping spider Portia labiata, Animal Behaviour 58 (1999), pp. 255-265.

Williams and McIntyre, 1980 - D.S. Williams and P. Mclntyre, The principal eyes of a jumping spider have a telephoto component, Nature 288 (1980), pp. 578-580. 